\title{
Thermal Curing Behavior and Tensile Properties of Resole Phenol-Formaldehyde Resin/Clay/Cellulose Nanocomposite*1
}

\author{
Byung-Dae Park ${ }^{*} \dagger$ and John F. Kadla*3
}

\begin{abstract}
This study investigated the effects of layered clay on the thermal curing behavior and tensile properties of resole phenol-formaldehyde (PF) resin/clay/cellulose nanocomposites. The thermal curing behavior of the nanocomposite was characterized using conventional differential scanning calorimetry (DSC) and temperature modulated (TMDSC). The addition of clay was found to accelerate resin curing, as measured by peak temperature $\left(T_{p}\right)$ and heat of reaction $(\Delta \mathrm{H})$ of the nanocomposite' curing reaction increasing clay addition decreased $T_{p}$ with a minimum at $3 \sim 5 \%$ clay. However, the reversing heat flow and heat capacity showed that the clay addition up to $3 \%$ delayed the vitrification process of the resole PF resin in the nanocomposite, indicating an inhibition effect of the clay on curing in the later stages of the reaction. Three different methods were employed to determineactivation energies for the curing reaction of the nanocomposite. Both the Ozawa and Kissinger methods showed the lowest activation energy $(E)$ at $3 \%$ clay content. Using the isoconversional method, the activation energy $\left(E_{\alpha}\right)$ as a function of the degree of conversion was measured and showed that as the degree of cure increased, the $E_{a}$ showed a gradual decrease, and gave the lowest value at $3 \%$ nanoclay. The addition of clay improved the tensile strengths of the nanocomposites, although a slight decrease in the elongation at break was observed as the clay content increased. These results demonstrated that the addition of clay to resole PF resins accelerate the curing behavior of the nanocomposites with an optimum level of $3 \%$ clay based on the balance between the cure kinetics and tensile properties.
\end{abstract}

Keywords : cellulose, clay, cure kinetics, nanocomposite, resole phenolic resin, modulated differential scanning calorimetry, tensile properties

*1 Received on February 20, 2012; accepted on March 24, 2012

*2 Department of Wood Science and Technology, Kyungpook National University, Daegu 702-201, Republic of Korea

*3 Department of Wood Science, The University of British Columbia, Vancouver, B.C., V6T 1Z4, Canada

† Corresponding author : Byung-Dae Park (e-mail: byungdae@knu.ac.kr) 


\section{INTRODUCTION}

In recent years, there has been a tremendous increase in the amount of research, and the number of publications on nanocomposite using nanomaterials such as carbon nanotubes (Shen et al., 2007; Coleman et al., 2006), nanoclay (Tjong, 2006; Ray and Okamoto, 2003; Pavlidou and Papaspyrides, 2008), and nanofibers (Cheng et al., 2009; Prolongo et al., 2009). Nanomaterial-reinforced polymer composites have its roots in the pioneering work of researchers at Toyota (Kojima et al., 1993; Usuki et al., 1993). They first reported on the improvement inthe properties of nylon nanocomposites by incorporating nanoclay into the polymer matrix. Subsequently, an enormous amount of research has been done on nanocomposite materials based on a variety of polymers (Ray and Okamoto, 2003). Although the majority of research and development has focused on thermoplastics, a large volume of work has been done on nano-reinforced thermosetting polymers. In Particular, nanocomposites based on layered nanoclay and epoxy resins have been widely studied (Tjong, 2006; Ingram et al., 2007; McIntyre et al., 2005; Park and Jana, 2003). In these systems, the elastic forces exerted by the cross-linking epoxy molecules inside the clay galleries lead to clay exfoliation, and accelerate gel formation in the extra-gallery regions.

Among thermosetting polymers, phenol-formaldehyde (PF) resins are one of the most versatile resins, providing outstanding performance in adhesion, high temperature resistance, flame resistance and electric insulation. Thus, PF resins have been used to improve mechanical properties, moisture resistance, or fire resistance in many applications. For example, PF resin is impregnated into cellulose paper to fabricate decorative or protective laminates on the surface of wood-based composite products. These laminate papers are hot-pressed onto the surface of composite wood products to provide a hard surface finish.

In general, PF resin has a three dimensional structure, which makes it tough for the layered silicate gallery to intercalate even if the lamella of the layered silicate can be easily intercalated by linear polymers. Therefore, a limited number of attempts have been made to understand layered silicates in PF resins. Early studies on organoclay reinforced linear novolac PF resin nanocomposite demonstrated that the structural affinities between the clay modifier and the polymer enhance intercalation (Choi et al., 2000; 2003). The same research group also reported an ideal silicate concentration of $3 \%$ which greatly improved tensile strength, tensile modulus, toughness, and elongation-at-break (Byun et al., 2001).

The first study on producing nanocomposites from resole PF resins demonstrated that exfoliation was more difficult with resole PF resins than novolac PF resins, since the former possessed more three-dimensional structure even prior to curing (Wang et al., 2004). However, the authors reported that $3 \sim 5 \%$ clay in resole PF resins was completely exfoliated, thereby significantly improving impact strength of the resultant nanocomposite. Employing a suspension condensation polymerization method, $\mathrm{Wu}$ et al. (2002) showed that both novolac and resole PF resins was suitable for preparation of PF resin/clay nanocomposite. However, they also reported that the clay exfoliation or intercalation in novolac was easier than in resole. Kaynak and Tasan (2006) also showed that the cure method, clay amount, and clay modification had significant impact on the mechanical properties of the PF resin/clay nanocomposites. The same group found that unmodified pristine Na-montmorillonite clay provided better strength improvement, $\sim 16 \%$ in Charpy impact 
strength, and $66 \%$ in fracture toughness values (Tasan and Kaynak, 2009). These results suggested that nanoclay could be used to improve the properties of cellulose/PF resin-based surface laminates.

It is well known that; the curing behavior of PF resin-based nanocomposite is very important as it impacts the majority of properties in the resulting nanocomposite. However, the curing behavior of resole PF resin/clay/cellulose nanocomposites has not been fully investigated as a potential candidate for surface laminates. Consequently, the object of this study was to prepare nanocomposites based on resole PF resin, nanoclay, and cellulose paper, and to characterize the curing behavior and tensile properties of the resulting nanocomposite in order to assess the feasibility as surface laminates for wood-based composite products.

\section{MATERIALS and METHODS}

\subsection{Materials}

A commercial resole PF resin tailored for the impregnation of paper laminates was donated by a local resin company (Tae Yang Chemical Ltd. Co., Incheon, Korea). The resole PF resin had the formaldehyde/phenol mole ratioof 2.2 and non-volatile solids content of $48.2 \%$, and was used as received. The cellulose paper used for the impregnation of PF resin/clay mixtures was donated by a local low pressure laminate (LPL) manufacturer (Samsun Gratech Inc., Incheon, Korea). It was a grade of LPL with a basis weight of $80 \mathrm{~g} / \mathrm{m}^{2}$.

Cloisite ${ }^{\circledR}-\mathrm{Na}^{+}$clay, a hydrophilic, pristine montmorillonite was purchased from Southern Clay Products Inc., Texas, USA. The clay had a density of $2.86 \mathrm{~g} / \mathrm{cm}^{3}$ and more than $90 \%$ of its particles were greater than $13 \mu \mathrm{m}$ in size. It was used without further treatment.

\subsection{Preparation of Nanocomposite}

Clay particles and PF resin were stirred by hand in order to produce mixtures with $0,1,3$, 5 and $10 \mathrm{wt} \%$ clay. The clay particles were subsequently dispersed in the resin by ultrasonication at $700 \mathrm{~W}$ for $30 \mathrm{~min}$. The ultrasonicator had a $135 \mathrm{~mm}$ long horn. These mixtures were impregnated into cellulose paper by soaking the paper into the clay/resin mixture, subsequently removing excess resin with a roller. The resulting impregnated paper had a target resin loading of $60 \%$, which gave a paper weight of about $200 \mathrm{~g} / \mathrm{m}^{2}$. The resin impregnated papers were dried at room temperature for three hours and then pre-curedat $60^{\circ} \mathrm{C}$ in a drying oven overnight. These nanocomposite samples were stored in a desiccator for future analysis.

\subsection{DSC Measurements of the Nano- composite}

About $5 \mathrm{mg}$ of the nanocomposite sample was weighed into a hermetic aluminum pan and then scanned using a TMDSC (Q1000, TA Instruments, New Castle, DE, USA). For dynamic scanning, 5, 10, 15 and $20^{\circ} \mathrm{C} / \mathrm{min}$ heating rates were used for each clay level. The conventional DSC scans were conducted in duplicate over the temperature range from 30 to $300^{\circ} \mathrm{C}$.

The samples were also run from -50 to $300^{\circ} \mathrm{C}$ with a TMDSC option and a heating rate of $5^{\circ} \mathrm{C} / \mathrm{min}$., amplitude of $\pm 0.66^{\circ} \mathrm{C}$, a period of $50 \mathrm{~s}$, and a mass of approximately $2 \mathrm{mg}$ in the same type of aluminum pan. These parameters were chosen to maintain 'heat only' condition during a TMDSC scan. 


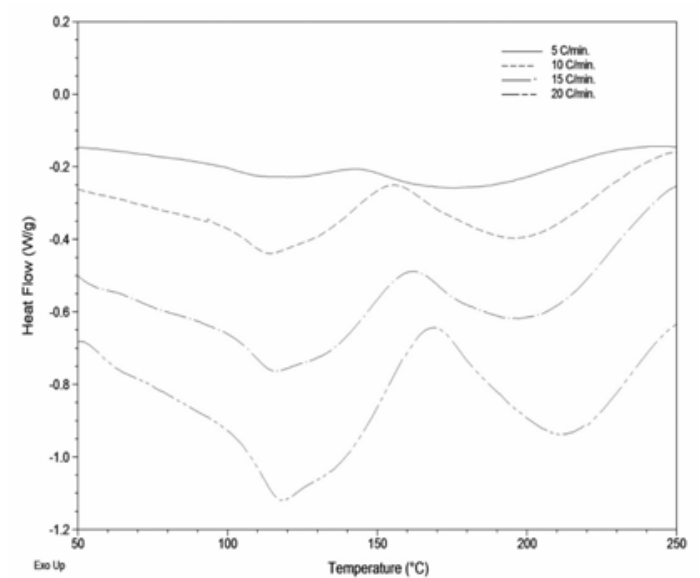

Fig. 1. Typical DSC thermograms for the control nanocomposites ( $0 \%$ clay) at different heating rates.

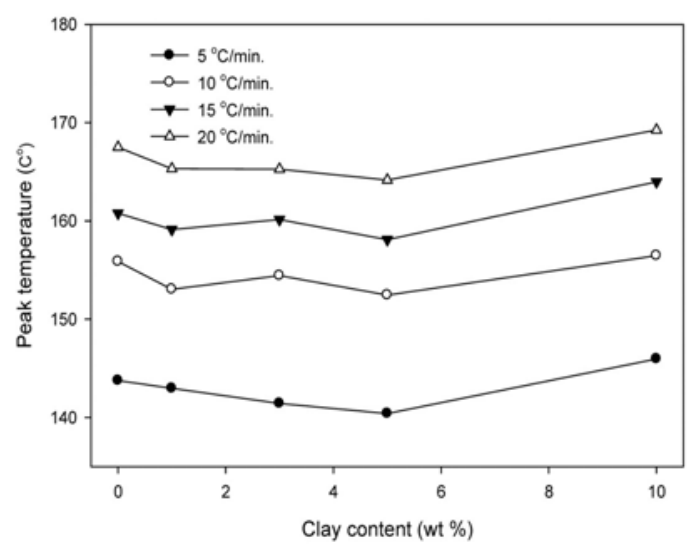

Fig. 2. Effect of clay addition on the peak temperature $\left(T_{p}\right)$ for resole $\mathrm{PF}$ resin/clay/cellulose nanocomposites at different heating rates.

\subsection{Measurements of tensile proper- ties of the nanocomposite}

The tensile tests were performed using a testing machine (model 3343, Instron, USA with a load cell of $1 \mathrm{kN})$. The cross head speed was $5 \mathrm{~mm} / \mathrm{min}$. The specimens were cut with width of $15 \mathrm{~mm}$ and a length of $50 \mathrm{~mm}$. The thick- ness of samples was calculated before test. The gauge between top and bottom clamp was 25 $\mathrm{mm}$.

\section{RESULTS and DISCUSSION}

\subsection{Cure Kinetics by the Ozawa and Kissinger Methods Using Con- ventional DSC}

Fig. 1 shows the typical DSC thermograms for the control (no clay) composites at different heating rates $\left(5 \sim 20^{\circ} \mathrm{C} / \mathrm{min}\right)$. In all cases, there is an initial decrease in heat flow as temperature is increased. This is likely due to the softening of the impregnated resole PF resins prior to curing. After reaching a minimum, the heat flow increases to a maximum peak temperature $\left(T_{p}\right)$ due to the exothermic curing of the resole PF resins.

Fig. 2 shows the variation in $T_{p}$ for the various nanocomposites with different clay contents and DSC heating rates. As the clay content increased, the $T_{p}$ decreases up to $3 \sim 5 \%$ clay, and then increases upon further addition to $10 \%$ clay regardless of the heating rate. This result suggeststhat the addition of $3 \sim 5 \%$ clay to the resole PF resin accelerates curing of the nanocomposite. The accelerated cure rate could be caused by the Lewis acidity of the clay used in this study (Yong et al., 1997). Clay cations like $\mathrm{Al}^{3+}, \mathrm{Fe}^{3+}$, or $\mathrm{Na}^{+}$act as Lewis acids, which can accept electrons from various aromatic compounds (Lopez et al., 2008; 2009). The oxidizing power of the clay is proportional to its Lewis acidity. However, the addition of more than $10 \%$ clayretarded the cure rate, possibly due to agglomeration and, consequently, poor dispersion throughout the nanocomposite. As expected, the $T_{p}$ of the nanocomposite increased as the heating rate increased. This result suggeststhat the curing of the resole PF resin is a 


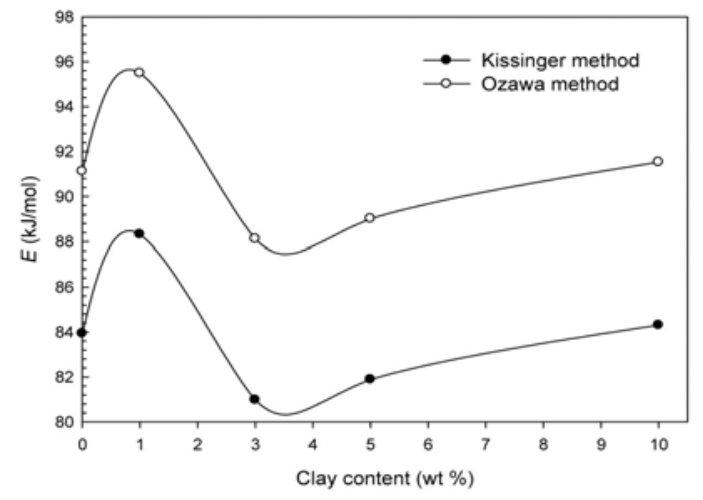

Fig. 3. Activation energy $(E)$ of resole PF resin/clay/cellulose nanocomposites as a function of the clay content using the Kissinger and Ozawa methods.

function of temperature, which makes it possible to calculate the activation energy by applying different methods such as the Ozawa, Kissinger and isoconversional methods.

DSC is typically used to monitor either heat evolution or absorption for any reactions that may have taken place during the heating process. The basic assumption underlying the application of conventional DSC to cure kinetics is that the measured heat flow $(d \mathrm{H} / d \mathrm{t})$ is proportional to the reaction rate $(d \alpha / d \mathrm{t})$. In practice, it has proven to be a good assumption. All kinetic analysis of non-isothermal data is based on the following equation (Park et al., 1999):

$$
\frac{d \alpha}{d t}=\beta \frac{d \alpha}{d T}=Z \exp \left(-\frac{E}{R T}\right) f(\alpha)
$$

Typically, multi-heating rate methods such as the Ozawa, Kissinger, and isoconversional methods are utilized. The Ozawa method is based on a simple relationship between the activation energy $(E)$ and the heating rate $(\beta)$ (Ozawa, 1965). If the sample temperature is increased by a controlled and constant $\beta$, the variation in the degree of conversion can be an- alyzed as a function of temperature, this temperature being dependent on the time of heating. Therefore, this method relates heating rate to $E$, as is shown by the Eq. (2), and permits the calculation of $\mathrm{E}$ from a plot of $\log \beta$ versus $1 / T_{p}$.

$$
\log \beta=-2.315-0.456\left(\frac{E}{R T_{p}}\right)+\log \left(\frac{Z E}{R}\right)-\log F(\alpha)
$$

The Kissinger (1957) suggests a similar relationship:

$$
-\ln \left(\frac{\beta}{T_{p}^{2}}\right)=\frac{E}{R T_{p}}-\ln \left(\frac{Z R}{E}\right)
$$

where again, $E$ is can be calculated from the slope of the straight line generated from a plot of $-\ln \left(\beta / T_{p}^{2}\right)$ and $1 / T_{p}$, and the pre-exponential factor $(Z)$ from the $y$-intercept. Thus, the Kissinger method provides a single value of activation energy for the whole reaction process.

Fig. 3 illustrates the changes in of the $E$ determined by the Ozawa and Kissinger methods using Eq. (2) and (3), respectively. The $E$ values obtained by the Ozawa method were greater than those of the Kissinger method. However, the $E$ values obtained by both methods behave almost identically with increasing clay content. The higher $E$ values obtained using the Ozawa method is consistent with the results previously reported for resole PF resins (Alonso et al., 2004). As the clay was increased, the $E$ values determined using both methods increased to a maximum at $1 \%$ clay content and then decreased to a minimum at $3 \%$ clay content followed by a slow increase to $10 \%$ clay content.

The increase in $E$ value at $1 \%$ clay could be due to exfoliation of the clay. It has been reported that the presence of exfoliated clays act 

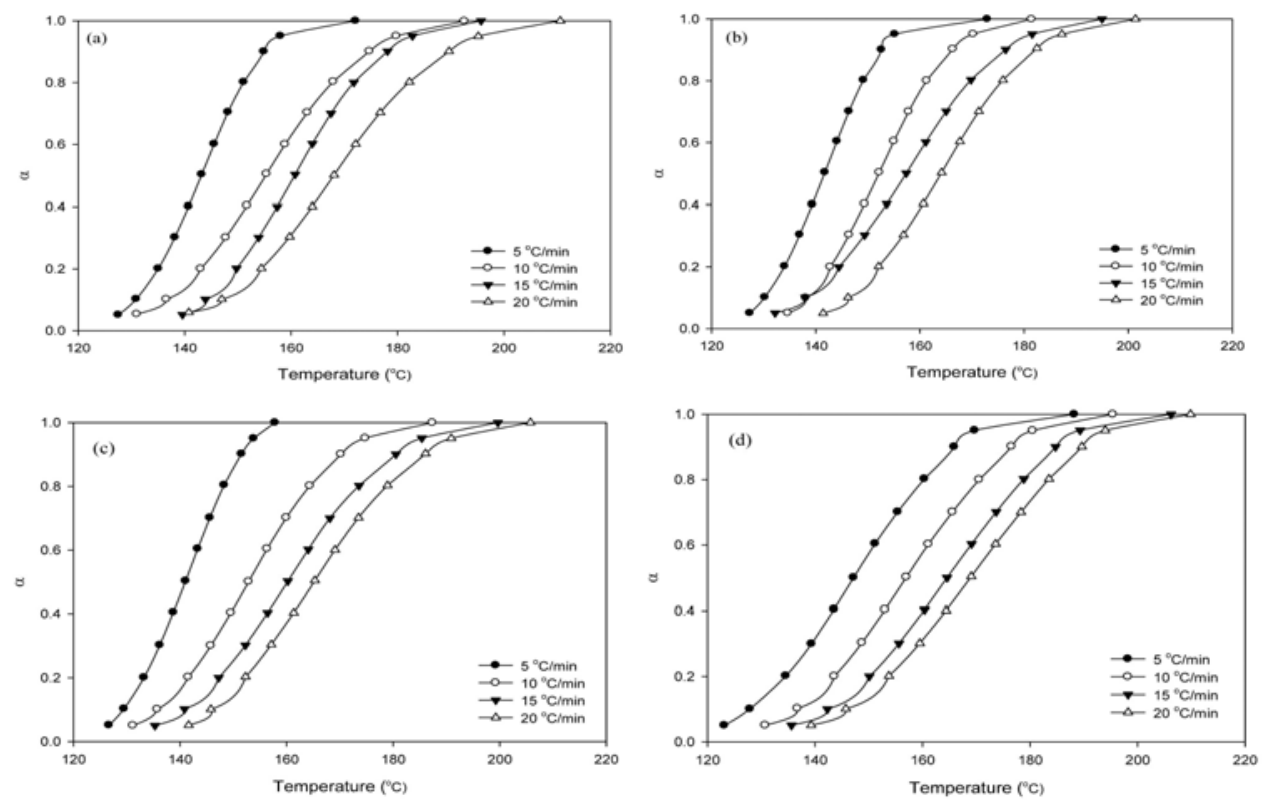

Fig. 4. Apparent degree of conversion versus temperature profiles for the resole PF resin/clay/cellulose nanocomposites at different clay levels and heating rates. (a) $0 \%$ clay, (b) $1 \%$ clay (c) $3 \%$ clay, and (d) $10 \%$ clay.

as a barrier to networkformation during the curing of epoxy resins (McIntyre et al., 2005). Thus, a similar effectmay likely be happening here, wherein the exfoliated clay increase the activation energy for the cross-linking process. Another possibility is that at $1 \%$ clay loading, there is increased inhomogeneity in the nanocomposite, which acts as a barrier to the curing of the resole PF resin. More work is required to clearly explain what factors contribute to this phenomenon.

\subsection{Cure Kinetics by the isocon- versional method using con- ventional DSC}

A third kinetic method is the isoconversional kinetic analysis or so-called "model-free kinetics" method, and has been used to characterize cure kinetics of both neat and modified PF resins (Kissinger, 1957; He et al., 2003; He and Riedl, 2004; Vyazovkin and Sbirrazzuoli, 2006; Wang et al., 2005; Alonso et al., 2004; Tejado et al., 2008; Lopez et al., 2008; 2009). This method requires a series of experiments performed at different temperature programs and yields the effective activation energy $\left(E_{\alpha}\right)$ as a function of conversion $(\alpha)$. In this case:

$$
-\ln \left(\frac{\beta_{i}}{T_{\alpha, i}^{2}}\right)=\frac{E_{\alpha}}{R T_{\alpha, i}}-\ln \frac{Z_{\alpha} R}{E_{\alpha}}
$$

where $\beta$ is the heating rate, $T$ is temperature $(i$ denoting thedifferent heating rates), $R$ is the gas constant, and $Z$ is the pre-exponential factor. $E_{\alpha}$ can be calculated from the slope of the plot of $-\ln \left(\beta_{i} / T_{\alpha}^{2}\right)$ vs. $1 / T_{\alpha}$, and the pre-exponential factor from the intercept.

Fig. 4 illustrates the relationships between the 
degree of conversion and temperature profiles for various resole PF/clay nanocomposites. Comparing the various profiles the clear impact of clay content on curing rate is evident; the curing reaction was accelerated as the clay content increased from 0 to $3 \%$ and then retarded with further increases to $10 \%$ clay content. As anticipated, the cure temperature decreases with increasing clay loading up to $3 \%$ clay, and then increased with further clay addition. At the same degree of conversion ( $\alpha=0.4)$ and heating rate $\left(5^{\circ} \mathrm{C} / \mathrm{min}\right)$, the cure temperatures for the resole PF resins were 141, 139, 139 and 164 for $0,1,3$ and $10 \%$ clay levels, respectively.

Using the isoconversional method the $E_{\alpha}$ as a function of $\alpha$ was calculated and is presented in Fig. 5. All of the resole PF resin/clay nanocomposites showed similar behavior in calculated $E_{\alpha}$ values as a function of degree of conversion $(\alpha)$. For all clay contents there was an initial sharp decrease in $E_{\alpha}$ at $\alpha$ up to 0.1 , followed by a slow gradual decrease with increasing degree of conversion $\alpha$. At $\alpha>0.9$ all of the nanocomposites showed an increase in $E_{\alpha}$ except for the $3 \%$ clay nanocomposites with sharply decreased. The $E_{\alpha}$ values ranged from 40 to $187 \mathrm{~kJ} / \mathrm{mol}$, with those obtained for $\alpha$ between 0.1 and 0.9 falling within the reported range between $60 \sim 120 \mathrm{~kJ} / \mathrm{mole}$ for the cure of resole PF resins (Yong et al., 1997; Park et al., 2002; Wang et al., 2005). The reduction in $E_{\alpha}$ values with increasing $\alpha$ between 0.1 and 0.9 could be ascribed to a cure acceleration of resole PF resins by the clay. In fact, a similar trend in $E_{\alpha}$ value has been reported for resole $\mathrm{PF}$ resins (He et al., 2003; He et al., 2005). An interesting point is that the $E_{\alpha}$ of the nanocompositewith $10 \%$ clay does not seem to decrease with increasing $\alpha$ as per the other clay loadings, which may suggest a different curing behavior. This may be due to agglomeration of clay particles in the resole PF resins, which hin-

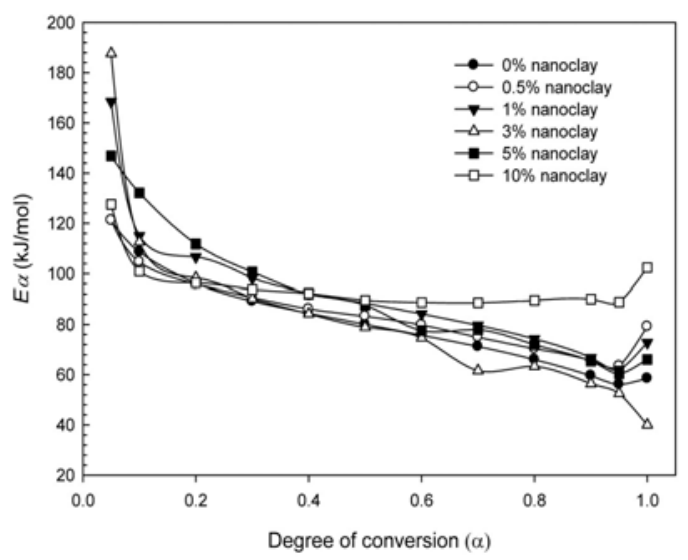

Fig. 5. Relationship between $E_{\alpha}$ and degree of conversion for the resole PF resin/clay/cellulose nanocomposite at different clay contents.

der resin network formation as a result of the increased $E_{\alpha}$. As well this may be a result of transition from a chemical-controlled curing reaction regime to one controlled by diffusion (Tejado et al., 2008).

\subsection{Cure Kinetics by Temperature Modulation using TMDSC}

To further study the cure kinetics of the resole $\mathrm{PF}$ resin/clay nanocomposites temperature modulated DSC (TMDSC) was utilized. Unlike conventional DSC, TMDSC permits simultaneous measurement of heat flow and heat capacity by applying the sinusoidal oscillation on a DSC temperature ramp and separately analyzing the sinusoidal and non-sinusoidal response (Reading et al., 1992; 1994). In particular, this technique has received considerable attention for monitoring the cure kinetics of thermosetting systems (Van Assche et al., 1995; 1996; 1997). In TMDSC, the heat flow equation has the following form: 


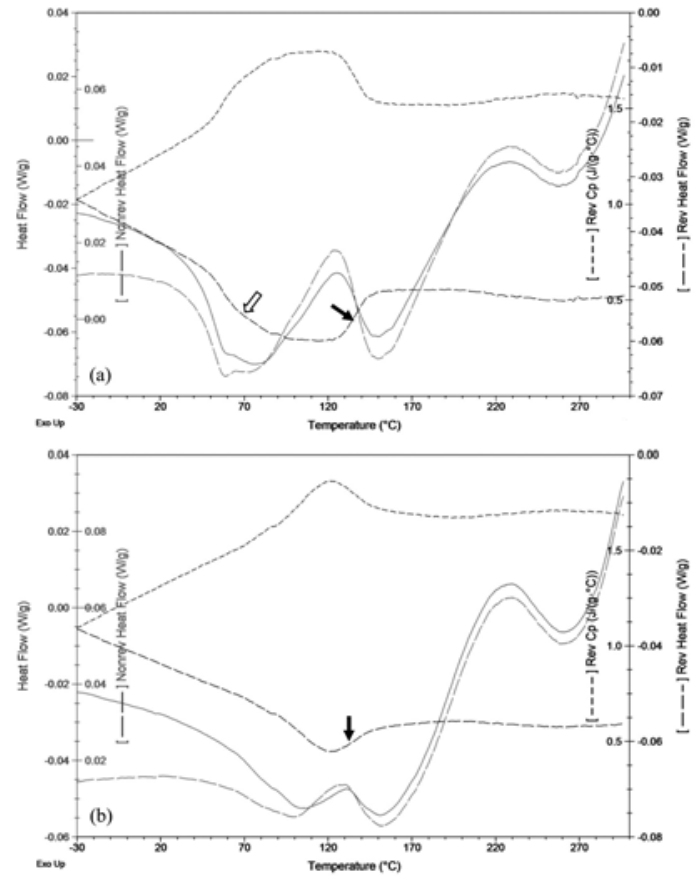

Fig. 6. Typical TMDSC thermograms for the resole $\mathrm{PF}$ resin/clay/cellulose nanocomposites at (a) $0 \%$ clay, and (b) $3 \%$ clay contents. Included are the total heat flow (solid line), reversing heat flow (medium dash line), non-reversing heat flow (long dash line) and reversing heat capacity (short dash line) curves.

$$
\frac{d H}{d t}=C_{p} \frac{d T}{d t}+f(t, T)
$$

where $d H / d T$ is the total heat flow $(\mathrm{J} / \mathrm{s}$ or $\mathrm{W})$, $C_{p}$ is the heat capacity $(\mathrm{J} / \mathrm{K})$ and $d T / d t$ is the heating rate. The reversing heat flow component ' $C_{p}(\mathrm{~d} T / \mathrm{d} t)$ ' is dependent on the rate of change of temperature and the heat capacity. The reversing heat flow includes the glass transition, and the melting of slow-melting polymers, or highly impure materials. By contrast, the 'nonreversing' heat flow component, $f(t, T)$, contains the heat flow contribution from kinetically controlled events that are dependent on both temperature and time. So, the non-reversing heat flow contains all kinds of kinetic transitions such as crystallization, curing reactions, evaporation, degradation, and the melting of fastmelting polymers and pure crystalline materials. The $C_{p}$ component is calculated from the response to the oscillation via

$$
C_{p}=K \frac{A_{m h f}}{A_{m h r}}
$$

where $A_{m n f}$ is the amplitude of the modulated heat flow, $A_{m h r}$ is the amplitude of the heating rate signal and $K$ is the heat capacity calibration constant. The non-reversing signal is calculated as the difference between the total heat flow response and the reversing signal which is obtained from the Eq. (5).

Fig. 6 shows the typical dynamic TMDSC thermograms for the control nanocomposite without clay, and the nanocomposite with $3 \%$ clay; included are the total, reversing, non-reversing heat flows, and the reversing heat capacity curves. The total and non-reversing heat flow curves were very close to each other and displayed an exothermic reaction due to the curing of resole PF resin (Fig. 6(a) and 6(b)). This phenomenon was pretty much the same for the nanocomposite of with clay contents greater than $3 \%$. This suggeststhat the curing reaction of resole PF resin becomes a predominant event in the thermal behavior of the nanocomposite. However, the reversing heat flow curve of the control nanocomposite shows a rapid decrease around $57.8^{\circ} \mathrm{C}$ (empty arrow in Fig. 6(a)) and then an increase around $136.7^{\circ} \mathrm{C}$ (filled arrow in Fig. 6(a)). As temperature increases, the resole $\mathrm{PF}$ resin softens to a molten state at first, and then starts to cure by cross-linking, leading to a network formation. After reaching the maximum cure rate at a peak temperature, vitrification begins. Vitrification is a transition from a liquid-rubberystate with high molecular mobility to 


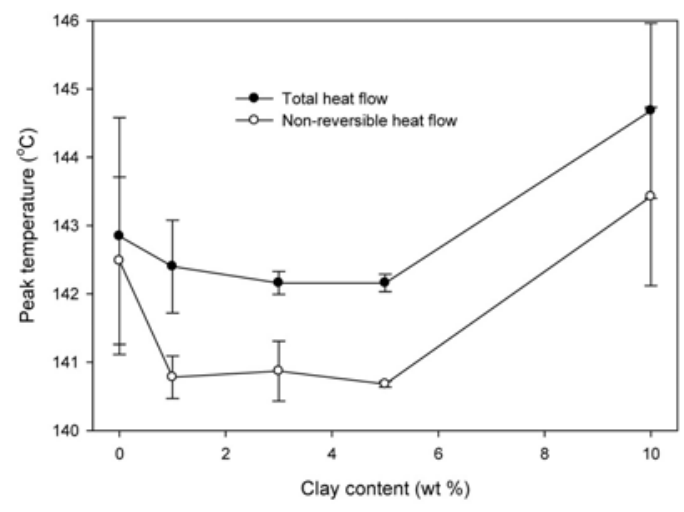

Fig. 7. Effects of clay content on the $T_{p}$ of the resole $\mathrm{PF}$ resin/clay/cellulose nanocomposite as determined by TMDSC.

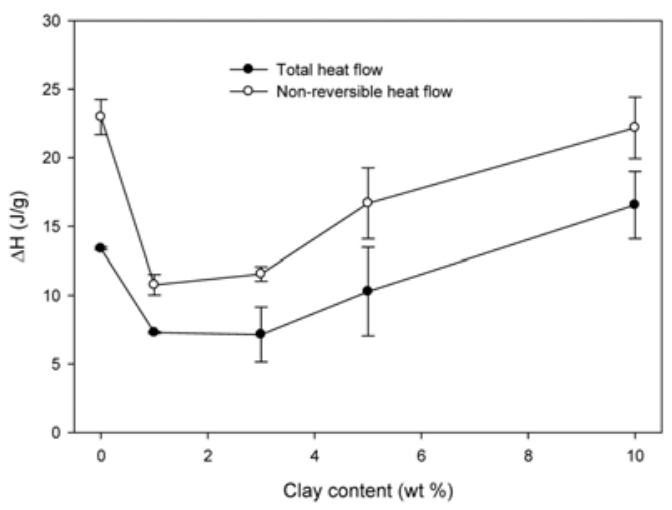

Fig. 8. Effect of clay content on the curing reaction heat $(\Delta \mathrm{H})$ of the resole PF resin/clay/cellulose nanocomposite as determined by TMDSC.

a glassy state with much lower molecular mobility. The reversing heat capacity of the nanocomposite was closely related to the exothermic cure reaction of the resole $\mathrm{PF}$ resin gradually decreasing from a maximum to lower values as the resole PF resin changed from a gel state to a glassy state. The dynamic vitrification temperature $\left(T_{d v}\right)$ was defined as the midpoint of the reversible heat flow curve right after the endothermic peak (filled arrow in Fig.

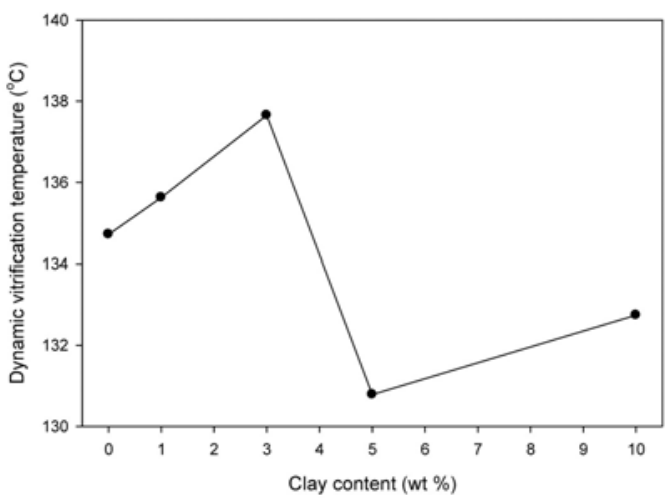

Fig. 9. Effect of clay content on the dynamic vitrification temperature $\left(T_{d v}\right.$. $)$ of the resole $\mathrm{PF}$ resin/clay/cellulose nanocomposite determined from the reversing heat flow of the TMDSC thermograms.

6(a) and 6(b)).

As for the conventional DSC, the TMDSC thermograms also provided $T_{p}$ values for the resole PF resin cure in the nanocomposite. Fig. 7 illustrates the effect of clay content on the $T_{p}$ values. The $T_{p}$ values from both total heat flow and non-reversing heat flows of the clay nanocomposites decreased with increasing clay content up to $5 \%$, and then rapidly increased at $10 \%$ clay content. This is again consistent with a cure acceleration of resole PF resin by adding clay as shown in Fig. 2. In fact, the $T_{p}$ range of the total heat flow from the TMDSC was quite similar to that from conventional DSC at a heating rate of $5^{\circ} \mathrm{C} / \mathrm{min}$. However, the $T_{p}$ values obtained from the non-reversing heat flow were lower than those from the total heat flow curve. This is because the non-reversing heat flow is equal to the difference between the total heat flow and the reversing heat flow for the nanocomposites. That is, the $T_{p}$ of the non-reversing heat flow from TMDSC represents only the cure of resole PF resin in the nanocomposite.

However, the curing reaction heat $(\Delta \mathrm{H})$ val- 
Thermal Curing Behavior and Tensile Properties of Resole Phenol-Formaldehyde Resin/Clay/Cellulose Nanocomposite

Table 1. Tensile strength and elongation of the resole PF resin/clay/cellulose nanocomposites as a function of the clay content

\begin{tabular}{ccc}
\hline Clay content $(\mathrm{wt} \%)$ & Tensile strength $(\mathrm{kN} / \mathrm{m})^{*}$ & Elongation $(\%)^{*}$ \\
\hline \hline 0 & $4.74 \pm 1.608$ & $0.96 \pm 0.288$ \\
1 & $7.52 \pm 1.829$ & $0.88 \pm 0.196$ \\
3 & $6.84 \pm 1.631$ & $0.79 \pm 0.160$ \\
5 & $6.98 \pm 2.065$ & $0.77 \pm 0.213$ \\
10 & $6.70 \pm 1.923$ & $0.83 \pm 0.243$ \\
\hline
\end{tabular}

*The values are presented an average and standard deviation.

ues from the total and non-reversing heat flow curves were greater than those obtained from the total heat flow of the nanocomposite. Fig. 8 shows that the $\Delta \mathrm{H}$ values for the total and non-reversing heat flows decreased with increasing clay content up to $\sim 3 \%$ and then increased as clay content increased. Again, this could be due to the cure acceleration effect of the added clay the addition of clay accelerates the cure of resole PF resin by lowering the $T_{p}$, which results in a decrease in the area under the exothermic curve $(\Delta \mathrm{H})$.

Fig. 9 shows the relationship between $T_{d v}$ and clay content for the resole $\mathrm{PF}$ resin/clay nanocomposites. As the clay content increased, the $T_{d v}$ increased reaching a maximum at $3 \%$ clay content. Increasing the clay content beyond $3 \%$ led to a sharp decrease in $T_{d v}$. This indicates that the vitrification of the resole PF resin is delayed up to a clay content of $3 \%$. Thus, the addition of clay restricted the vitrification process even though it accelerated the initial cure reaction in the nanocomposites. The lower $T_{d v}$ values at clay contents of 5 and $10 \%$ could also be due to an aggregation of the clay particles, resulting in an increased viscosity of resole $\mathrm{PF}$ resin as per finding for epoxy resin curing (Fraga et al., 2008).

\subsection{Tensile Properties of the Nano- composites}

The effect of clay addition on the mechanical properties of the resole PF resin/clay nanocomposites is presented in Table 1. When compared to the control nanocomposite (i.e., the ones lacking clay), tensile strength of the nanocomposite was improved by the addition of $1 \%$ clay tensile strength decreased at higher clay contents. These results show are inforcement effect of the added clay in the nanocomposite through either exfoliation or intercalation. As shown in Table 1, the elongation at break was reduced up to $3 \%$ clay and then leveled off afterwards. Since the added clay reinforced resole PF resin matrix in the nanocomposite, the resultant nanocomposite consequently became stiffer, which reduced the elongation at break.

\section{CONCLUSIONS}

This study investigated the thermal curing behavior and tensile properties of resole phenol-formaldehyde (PF) resin/clay/cellulose nanocompositeas a potential surface laminate material for wood-based composite panels. In order to study influences of clay addition on the thermal curing behavior of the nanocomposite, two different calorimetric techniques (DSC and TMDSC) 
were employed. As the clay content increased, $T_{p}$ values of the nanocompositecuring reaction decreased up to $3 \sim 5 \%$ clay content, showing the cure acceleration effect of the clay. The Ozawa, Kissinger, and isoconversional DSC methods were employed to determine activation energies for the curing reaction of the nanocomposite. Both the Ozawa and Kissinger method showed the lowest $E$ at $3 \%$ clay content. The isoconversional method provided the $E_{\alpha}$ as a function of the degree of conversion, wherein the $E_{\alpha}$ showed a gradual decrease with increasing degree of conversion, the lowest value at $3 \%$ clay loading. TMDSC further confirmed the cure acceleration effect of clay addition to the resole PF resin system, as indicated both $T_{p}$ and heat of reaction $(\Delta \mathrm{H})$ measurements. Interes- tingly, the reversing heat flow and heat capacity values showed that the addition of clay up to $3 \%$ delayed the vitrification process of $\mathrm{PF}$ resin in the nanocomposite, indicating an inhibition effect of the clay in the final stage of the curing reaction. Tensile strengths of the nanocomposite were slightly improved by the addition of small amounts of layered clay, showing a reinforcing effect, while the elongation at break slightly decreased as the clay content increased. These results demonstrate that an optimum level of clay addition to resole $\mathrm{PF}$ resin/cellulose nanocomposites is a balance between the impact on cure kinetics and tensile strength.

\section{REFERENCES}

1. Alonso, M. V., M. Oliet, J. M. Perez, F. Rodriguez, and J. Echeverria. 2004. Determination of curing kinetic parameters of lignin-phenol-formaldehyde resol resins by several dynamic differential scanning calorimetry methods. Thermochim. Acta 419: 161 167.

2. Byun, H. Y., M. H. Choi, and I. J. Chung. 2001.
Synthesis and Characterization of resol type phenolic resin/layered silicate nanocomposite. Chem. Mater. 13: $4221 \sim 4226$.

3. Cheng, Q., S. Wang, and T. G. Rials. 2009. Poly(vinyl alcohol) nanocomposite reinforced with cellulose fibrils isolated by high intensity ultrasonication. Composites: Part A. 40: 218 224.

4. Choi, M. H., I. J. Chung, and J. D. Lee. 2000. Morphology and curing behaviors of phenolic resin-layered silicate nanocomposite prepared by melt intercalation. Chem. Mater. 12: 2977 2983.

5. Choi, M. H. and I. J. Chung. 2003. Mechanical and thermal properties of phenolic resin-layered silicate nanocomposite synthesized by melt intercalation. J. Appl. Polym. Sci. 90: 2316 2321.

6. Coleman, J. N., U. Khan, W. J. Blau, and Y. K. Gun'ko. 2006. Small but strong: A review of the mechanical properties of carbon nanotube- polymer composites, Carbon 44: 1624 1652.

7. Fraga, I., S. Montserrat, and J. M. Hutchison. 2008. Vitrification during the isothermal cure of thermosets. Part I. An investigation using TOPEM, a new temperature modulated technique. J. Therm. Anal. Cal. 91: $687 \sim 695$.

8. Gill, P. S., S. R. Sauerbrunn, and M. Reading. 1993. Modulated differential scanning calorimetry. J. Thermal. Anal. 40: 931 939.

9. He, G. B., B. Riedl, and A. Ait-Kadi. 2003. Model-free kinetics: Curing behavior of phenol formaldehyde resins by differential scanning calorimetry. J. Appl. Polym. Sci. 87: 433 440.

10. He, G. B. and B. Riedl. 2004. Curing kinetics of phenol formaldehyde resin and wood-resin interactions in the presence of wood substrates. Wood Sci. Tech. 38: $69 \sim 81$.

11. Ingram, S., I. Rhoney, J. J. Liggat, N. E. Hudson, and R. A. Pethrick. 2007. Some factors influencing exfoliation and physical property enhancement in clay epoxy resins based on diglycidyl ethers of bisphenol A and F. J. Appl. 
Thermal Curing Behavior and Tensile Properties of Resole Phenol-Formaldehyde Resin/Clay/Cellulose Nanocomposite

Polym. Sci. 106: 5 19.

12. McIntyre, S., I. Kaltzakorta, J. J. Liggat, R. A. Pethrick, and I. Rhoney. 2005. Influence of the epoxy structure on the physical properties of epoxy resin nanocomposite, Ind. Eng. Chem. Res. 44: $8573 \sim 8579$.

13. Kaynak, C. and C. C. Tasan. 2006. Effects of production parameters on the structure of resol type phenolic resin/layered silicate nano- composite. Euro. Polym. J. 42: 1908 1921.

14. Kissinger, H. E. 1957. Reaction kinetics in differential thermal analysis. Anal. Chem. 29: $1702 \sim 1706$.

15. Kojima, Y., A. Usuki, M. Kawasumi, A. Okada, T. Kurauchi, and O. Kamigaito. 1993. Synthesis of nylon 6-clay hybrid by montmorillonite intercalated with e-caprolactam. J. Polym. Sci. Part A: Polym. Chem. 31: 983 986.

16. López, M., M. Blanco, A. Vazquez, N. Gabilondo, A. Arbelaiz, J. M. Echeverría, and I. Mondragon. 2008. Curing characteristics of resol-layered silicate nanocomposites. Thermchim. Acta. 467: $73 \sim 79$.

17. López, M., M. Blanco, A. Vazquez, J. A. Ramos, A. Arbelaiz, N. Gabilondo, J. M. Echeverría, and I. Mondragon. 2009. Isoconversional kinetic analysis of resol-clay nanocomposite. J. Therm. Anal. Cal. 96: $567 \sim 573$.

18. Ozawa, O. A. 1965. A new method of analyzing thermogravimetric data. Bull. Chem. Soc. of Japan 38: 1881 1886.

19. Park, B. D., B. Riedl, H. J. Bae, and Y. S. Kim. 1999. Differential scanning calorimetry of phenol-formaldehyde adhesives. J. Wood Chem. Tech. 19: $265 \sim 286$.

20. Park, B. D., B. Riedl, Y. S. Kim, and W. T. So. 2002. Effect of synthesis parameters on thermal behavior of phenol-formaldehyde resole resin. J. Appl. Polym. Sci. 83: 1415 1424.

21. Park, J. H. and S. C. Jana. 2003. Mechanism of exfoliation of nanoclay particles in epoxy-clay nanocomposite. Macromol. 36: 2758 2768 .
22. Pavlidou, S. and C. D. Papaspyrides. 2008. A review on polymerlayered silicate nanocomposite. Prog. Polym. Sci. 33: 1119 1198.

23. Prolongo, S. G., M. Campo, M. R. Gude, R. Chaos-Moran, and A. Urena. 2009. Thermophysical characterization of epoxy resin reinforced by amino-functionalized carbon naonofibers. Composite Sci. Tech. 69: 349 357 .

24. Ray, S. S. and M. Okamoto. 2003. Polymer/ layered silicate nanocomposite: a review from preparation to processing. Prog. Polym. Sci. 28: $1539 \sim 1641$.

25. Reading, M., D. Elliott, and V. L. Hill. 1992. Some aspects of the theory and practice of modulated differential scanning calorimetry. In: Proceedings of the 21st NATAS Conference, pp. $145 \sim 150$.

26. Reading, M. 1993. Modulated differential scanning calorimetry- a new way forward in materials characterisation. Trends Polym. Sci. 8: 248 253.

27. Reading, M., D. Elliot, and V. L. Hill. 1993. A new approach to the calorimetric investigation of physical and chemical transitions. J. Thermal. Anal. 40: $949 \sim 955$.

28. Reading, M., A. Luget, and R. Wilson. 1994. Modulated differential scanning calorimetry. Thermochim. Acta, 238: 295 307.

29. Shen, J., W. Huang, L. Wu, Y. Hu, and M. Ye. 2007. Thermo-physical properties of epoxy nanocomposite reinforced with aminofunctiona lized multi-walled carbon nanotubes. Composites: Part A. 38: 1331 1336.

30. Tasan, C. C. and C. C. Kaynak. 2009. Mechanical performance of resol type phenolic resin/layered silicate nanocomposite. Polym. Compos. 30: $343 \sim 350$.

31. Tejado A., G. Kortaberria, J. M. Echeverria, and I. Mondragon. 2008. Isoconversional kinetic analysis of novolac-type lignophenolic resin cure. Thermchim. Acta 471: 80 85.

32. Tjong, S. C. 2006. Synthesis and Structure Pro- 
perty Characteristics of Clay Polymer Nanocomposite. In: Tjong, S.C. (ed), Nano-crystalline Materials, Elsevier Ltd., Chapter 10, pp: 311-348.

33. Usuki, A., Y. Kojima, M. Kawasumi, A. Okada, Y. Fukushima, T. Kurauchi, and O. Kamigaito. 1993. Synthesis of nylon 6-clay hybrid. J. Mater. Res. 8: $1179 \sim 1184$.

34. Van Assche, G., A. Van Hemelrijck, H. Rahier, and B. Van Mele. 1995. Modulated differential scanning calorimetry: isothermal cure and vitrification of thermosetting systems. Thermo- chim. Acta, 268: $121 \sim 142$.

35. Van Assche, G., A. Van Hemelrijck, H. Rahier, and B. Van Mele. 1996. Modulated differential scanning calorimetry: Non-isothermal cure, vitrification, and devitrification of thermosetting systems. Thermochim. Acta, 286: 209 224.

36. Van Assche, G., A. Van Hemelrijck, H. Rahier, and B. Van Mele. 1997. Modulated temperature differential scanning calorimetry; Consideration for aquantitative study of thermosetting systems. J. Therm. Anal. 49: 443 447 .

37. Vyazovkin, S. and N. Sbirrazzuoli. 2006. Isoconversional kinetic analysis of thermally stimu- lated processes in polymers. Macromol. Rapid Comm. 27: 1515 1532 .

38. Wang, J., M.-P.G. Laborie, and M. P. Wolcott. 2005. Comparison of model-free kinetic methods for modeling the cure kinetics of commercial phenol-formaldehyde resins. Thermochim. Acta 439: $68 \sim 73$.

39. Wang, H., T. Zhao, Y. Y and Y. Yu. 2004. Synthesis of resol-layered Silicate nanocomposite by reaction exfoliation with acid-modified montmorillonite, J. Appl. Polym. Sci. 92: 791 797.

40. $\mathrm{Wu}, \mathrm{Z}$., C. Zhou, and R. Qi. 2002. The preparation of phenolic resin/montmorillonite nanocomposite by suspension condensation polymerization and their morphology. Polym. Compos. 23: $634 \sim 646$.

41. Wunderlich, B., Y. Jin, and A. Boiler. 1994. Mathematical description of differential scanning calorimetry based on periodic temperature modulation, Thermochim. Acta 238: 277 293.

42. Yong, R. N., S. Desjardins, J. P. Farant, and P. Simon. 1997. Influence of $\mathrm{pH}$ and exchangeable cation on oxidation of methylphenols by a montmorillonite clay. Appl. Clay Sci. 12: 93 110 . 